* Artigo Original

\title{
Reflexões teórico-metodológicas para a interpretação das intervenções e do cuidado no território em saúde mental ${ }^{1}$
}

\author{
Mônica Lima \\ Instituto de Psicologia, Universidade Federal da Bahia (UFBA), Bahia, Brasil \\ molije@hotmail.com
}

\author{
Mônica de Oliveira Nunes \\ Instituto de Saúde Coletiva, Universidade Federal da Bahia (UFBA), Bahia, Brasil \\ nunesm@ufba.br
}

\author{
Vânia Sampaio Alves \\ Centro de Ciências da Saúde da Universidade Federal do Recôncavo da Bahia (CCS/UFRB), Bahia, \\ Brasil \\ vaniasampa@yahoo.com.br
}

Marcos Roberto Paixão Santos

Faculdade de Filosofia e Ciências Humanas, Universidade Federal da Bahia (FFCH/UFBA), Bahia, Brasil xmarcos1@gmail.com

DOI: $10.3395 /$ reciis.v5i4.560pt

\section{Resumo}

Neste artigo, apresentamos algumas reflexões teórico-metodológicas produzidas pelos integrantes do Núcleo de Estudos Interdisciplinares em Saúde Mental (NISAM/ISC/UFBA). Tais abordagens teóricometodológicas têm embasado o trabalho de campo e a análise de dados empíricos produzidos a partir de pesquisas recentes desenvolvidas no contexto de Centros de Atenção Psicossocial. Essas reflexões assumem como referências autores da Hermenêutica e da Antropologia Interpretativa. Com estudos e pesquisas que se alinham à investigação avaliativa no campo da saúde mental, o referencial teóricometodológico adotado pelo Nisam tem privilegiado desenhos metodológicos de cunho etnográfico, adotando a estratégia de triangulação de dados e de fontes de evidências a partir da confrontação do ponto de vista dos distintos atores sociais envolvidos na construção dos serviços e da rede de atenção em saúde mental - usuários, parentes, profissionais, gestores e comunidade.

Palavras-chave: Saúde Mental; CAPS; Avaliação de Serviços; Território; Cuidado em Saúde

\section{I ntrodução}

Como um dos resultados diretos do conjunto de debates tecidos a partir do Movimento pela Reforma Psiquiátrica no Brasil, a criação dos Centros de Atenção Psicossocial (CAPS) objetiva a reorientação do modelo de assistência em saúde mental, com intervenções no território como estratégia de promoção da reinserção social de pessoas com transtornos mentais severos e persistentes (BRASIL, 2002). De acordo com a política de saúde mental, as práticas desenvolvidas a partir dos CAPS devem ser comprometidas com a efetivação da desinstitucionalização e com a cidadania das pessoas com sofrimento mental, marcando uma distinção - diríamos, radical - entre um modelo hospitalocêntrico e um modelo de clínica ampliada, cujas potencialidades incluem o trânsito desses indivíduos no espaço social mais amplo.

Compreendemos que os CAPS constituem-se como microculturas, ou seja, como universos culturais próprios em interação com a sociedade na qual estão inscritos (NUNES et. al., 2010). Ao frequentarem os CAPS, as pessoas constroem e se utilizam de um conjunto de recursos, significantes, horizontes epistemológicos, temporalidades e disposições espaciais, ao que chamamos de idiomas culturais, gestados a partir de ideias e práticas desenvolvidos nos movimentos de Reforma Psiquiátrica localmente produzidos e contextualizados. As relações estabelecidas entre essas microculturas e o território mais vasto e a abertura dessas para sofrerem influência dos seus saberes e práticas e produzirem respostas em função das necessidades sociais que o território indica são, em grande medida, responsáveis pelo maior ou menor grau de desinstitucionalização obtido e de inclusão social dos usuários dos CAPS (SANTOS e NUNES, 2011). 
Ao mesmo tempo em que falamos da relação CAPS, enquanto microcultura, e território, o CAPS faz parte do território no qual está inscrito, transformando-o e sendo transformado pelo próprio território. Para estudá-lo, sugerimos que, no trabalho de campo em saúde mental, o conceito de território (e, também, o de CAPS) seja utilizado num sentido bem específico, qual seja, território como espaço (não delimitado geograficamente) que se constitui no uso que dele é feito. Concebendo o território como espaço apropriado pelo homem, o lócus de análise não é o espaço em si mesmo, mas as interações que são articuladas pelos indivíduos no uso de determinados espaços. Nesse sentido, os efeitos do CAPS e as articulações que ele propõe ultrapassam o seu limite espacial e acompanham as pessoas no seu devir social mais vasto.

Para estudar esses dispositivos, no que diz respeito à dinâmica das relações sociais que aí se desenvolvem, aos processos sociais que daí se depreendem e às articulações das experiências que por esse intermédio são produzidas, escolhemos aqui uma perspectiva fundamentalmente interpretativa. Para explicitá-la, neste artigo, compartilhamos algumas reflexões teóricometodológicas tecidas pelos autores e integrantes do Núcleo de Estudos Interdisciplinares em Saúde Mental (Nisam), do Instituto de Saúde Coletiva da Universidade Federal da Bahia (ISC/UFBA), para embasamento do trabalho de campo e análise de dados empíricos produzidos a partir de pesquisas recentes desenvolvidas no contexto de Centros de Atenção Psicossocial. Estas reflexões assumem como referências autores da Hermenêutica e da Antropologia Interpretativa. Com estudos e pesquisas que se alinham à investigação avaliativa no campo da saúde mental, o referencial teóricometodológico adotado pelo Nisam tem privilegiado desenhos metodológicos de cunho etnográfico, adotando a estratégia de triangulação de dados e de fontes de evidências a partir da confrontação do ponto de vista dos distintos atores sociais envolvidos na construção dos serviços e da rede de atenção em saúde mental - usuários parentes, profissionais, gestores e comunidade (MINAYO, 1991, 2005; FURTADO, 2001; ONOCKO-CAMPOS e FURTADO, 2006; FURTADO e CAMPOS, 2008).

\section{Hermenêutica: inspirações filosóficas e repercussões na Antropologia}

Etimologicamente, Hermenêutica remete aos processos de interpretação e compreensão. De acordo com Soares (1994), o debate sobre a Hermenêutica pode incorrer no equívoco de tomar por unívoco o que é polissêmico. O autor assinala a existência de múltiplas e, por vezes, contraditórias tradições hermenêuticas. Assim sendo, adverte-nos da necessidade do posicionamento teórico-filósofico.

A tradição hermenêutica desenvolve-se em contraposição à corrente positivista e sofre influência teórico-filosófica de autores como Hurssel, Dilthey, Scheleiermacher, Heidegger e Gadamer, segundo explicitação de Soares (1994). Dilthey afirma a historicidade do conhecimento, à qual atrela o pressuposto do pertencimento do ser humano. De acordo com Dilthey, a história é geradora de "particularidades, de experiências únicas, de sociedades e culturas singulares" (SOARES, 1994, p. 22). Nesse sentido, a essência do ser humano está no seu pertencimento. Essa categoria será mais tarde retomada por Gadamer, que afirma a finitude humana perante o seu pertencimento ao campo da linguagem.

A tese de linguisticidade é uma contribuição de Heidegger à teoria hermenêutica (CASAL, 1996). A linguagem, ao preceder e suceder ao ser humano, delimita o seu horizonte interpretativo, inscrevendo-o em uma tradição ou cultura. Situar-se na linguagem e na cultura significa limitar-se, renunciar à completude, à totalidade, à consciência plena, ao absoluto: significa reconhecer o limite da própria reflexividade (SOARES, 1994).

Uma concepção essencial da tradição hermenêutica, referenciada em Hurssel e em Gadamer, é a de que a interpretação do mundo, mesmo a científica, se dá a partir de pré-compreensões ou preconceitos, estando, portanto, condicionada a um horizonte específico. As pré-compreensões resultam de um ponto de vista prévio, certamente histórico, e podem ser consideradas como pressupostos da compreensão (CASAL, 1996).

A noção de horizonte implica, por sua vez, em condições de possibilidades de atribuição de sentido à realidade, uma espécie de quadro de referência. A Hermenêutica, para autores como Gadamer, resulta exatamente do diálogo estabelecido com as nossas pré-compreensões, determinadas pela tradição que nos constitui enquanto ser de linguagem e que condiciona nosso horizonte. Entretanto, se, por um lado, a noção de horizonte aponta para limites interpretativos, por outro, ela contempla a disponibilidade crítico-criativa, que propicia a incorporação de outras tradições, outras culturas, promovendo-se, então, a fusão de horizontes (SOARES, 1994). Esse é um dos conceitos pilares da teoria hermenêutica gadameriana.

A experiência hermenêutica envolve o encontro entre a historicidade do objeto (o Outro) e a historicidade de seu intérprete. Conforme enuncia Casal (1996, p. 58), "uma compreensão bem sucedida exige a conjunção, a fusão de dois horizontes: o horizonte do outro, do passado, da 
tradição; e o horizonte do eu, de cada um, da sua própria experiência no seu presente".

A noção de horizonte, portanto, caracteriza-se pela sua abertura e suscetibilidade de incorporar o ainda não-integrado, o novo. Nessa perspectiva, a atividade hermenêutica é construtiva e captadora, ativa e passiva. Percebe-se sempre de algum lugar, situado em algum plano, sediado em alguma cultura. Desse modo, admite-se que a interpretação hermenêutica impõe recortes ao objeto. Como ressalta Soares (1994), percebemos sempre através de um filtro seletivo. Isso acontece porque somos seres históricos, pertencentes a determinada linguagem e tradição. Assim, culturalmente marcados, somos finitos.

A Hermenêutica tem sido marcada pela dialética entre particular e universal, identidade e diferença, sujeito e objeto, pertencimento e distância, parte e todo, entre outros (SOARES, 1994). A historicidade do homem e dos fenômenos sociais, por exemplo, é determinante da particularidade do conhecimento e de seu objeto. Essa ideia contrapõe-se à factibilidade, à concepção de que a vida se reproduz segundo leis e regras.

O pertencimento, por sua vez, situa o intérprete frente ao objeto, oferecendo-Ihe um horizonte interpretativo. Todavia, o distanciamento pode possibilitar o ato criativo e crítico e, assim, a fusão de horizontes, ou seja, o encontro dialógico entre tradições e cultura. Quanto à relação dialética entre sujeito e objeto, admite-se, na tradição hermenêutica, que os primeiros não são sempre ativos e que os segundos nem sempre são externos e passivos. Sujeito e objeto, na perspectiva gadameriana, se codeterminam e, da fusão de seus horizontes, emerge o conhecimento.

Dentre os pares dialéticos, a relação parte-todo é aquela que, sem dúvida, mais tem caracterizado a abordagem hermenêutica. Essa relação encontra-se no cerne da teoria do círculo hermenêutico. De acordo com essa teoria, a prática hermenêutica envolve a complexa relação entre partes e todo, na qual cada fragmento (parte) tem seu sentido inscrito no todo que a inclui e a determina enquanto fragmento significativo. Por sua vez, o sentido do todo apenas pode ser apreendido a partir da articulação significativa entre os fragmentos (partes) que o constituem (SOARES, 1994; SCHLEIERMACHER, 2006).

A interpretação hermenêutica, de acordo com a referida teoria, resulta de um complexo investimento "reflexivo, compreensivo e imaginativo" (SOARES, 1994, p. 24). A circularidade desse empreendimento é emblemática. O ponto de partida é o fragmento da realidade que se apresenta ao aparelho perceptivo de forma tangencial e parcial. Com o propósito de apreender o seu significado, o intérprete elabora interpretações-tentativas ou hipóteses iniciais, aproximativas relativamente à totalidade do objeto.

Nessa operação, entrarão em jogo as pré-compreensões, determinadas, por sua vez, pela tradição em que se situa o intérprete. A elaboração de interpretações-tentativas, projetivas da totalidade, justifica-se pelo fato do sentido de toda parte ser necessariamente relacional, posicional. À medida que outros fragmentos ou partes da realidade se manifestam, a hipótese inicial quanto ao sentido do fragmento anterior em relação à totalidade projetada será reexaminada, podendo ser validada, ou não. Em caso de contradição, a hipótese precisará ser reformulada e assim sucessivamente.

O movimento interpretativo segue sua circularidade. Em realidade, conforme destaca Soares (1994), trata-se de um empreendimento sempre inconcluso. A compreensão hermenêutica resulta, enfim, de um recorte da realidade. A totalidade jamais poderá ser apreendida, podendo inclusive vir a se constituir em parte ou fragmento de outra cadeia interpretativa. O círculo interpretativo, portanto, jamais finda. Ele é interrompido, tendo em vista os processos dialógicos e os acordos entre os interlocutores virtuais. Na produção científica, o consenso entre pesquisadores quanto à pertinência e à plausibilidade da compreensão de um dado fenômeno social condiciona a interrupção do círculo hermenêutico, ao menos temporariamente.

A teoria hermenêutica acaba por realçar a relevância das relações entre os interlocutores para a produção do conhecimento. Os sujeitos participam do círculo hermenêutico, posicionando-se em relação aos seus objetos mediante operações dialógico-argumentativas. Nessas operações, faz-se necessária a incorporação do princípio da codeterminação entre parte e todo, assim como a codeterminação entre sujeito e objeto. Revela-se, então, a reflexividade da prática hermenêutica: o intérprete precisa incluir a si próprio, ou melhor, a sua própria interpretação, no círculo hermenêutico. Sujeito e objeto se encontram e se codeterminam, fazendo fundir seus horizontes e produzindo o conhecimento.

Na discussão sobre produção hermenêutica do conhecimento, Casal (1996, p. 50), aproximando-se da perspectiva gadameriana, afirma ser esta essencialmente dialógica: “o dispositivo metodológico essencial é o diálogo, diálogo entre indivíduos, diálogo entre observador e observado, diálogo entre 
interpretado e intérprete, independente da temporalidade de cada objeto".

A partir do diálogo opera-se a fusão de horizontes. Em consequência, o sentido apreendido é sentido compartilhado entre sujeito e objeto, intérprete e interpretado. Pode-se depreender dessa premissa que a interpretação hermenêutica implica na produção intersubjetiva do conhecimento.

O debate em torno da aplicação metodológica da hermenêutica é permeado pela multiplicidade de tradições teóricas. Para Soares (1994), que se posiciona entre as tradições gadamerianas, a Hermenêutica não pode ser confundida com um método. Seu caráter não é instrumental. Gadamer, como nos recorda Casal (1996), assumiu, no desenvolvimento da teoria hermenêutica, uma postura antimetodológica, debruçando-se em torno da questão da compreensibilidade: "como é possível a compreensão, que é a compreensão"? (CASAL, 1996, p. 57).

Nesse sentido, Soares (1994) refere Scheleimarcher para destacar que a Hermenêutica compreende um problema relevante em si mesmo, vislumbrando nessa premissa a contribuição da Hermenêutica para as ciências sociais e humanas. Por conseguinte, assinala que "cumpre à hermenêutica explorar a estrutura essencial do ato de interpretação, refletir sobre as suas condições de possibilidade, seus limites e as extraordinárias implicações derivadas da compreensão dessa estrutura e desse processo" (SOARES, 1994, p. 14). Em outras palavras, a Hermenêutica consistiria essencialmente numa prática reflexiva do próprio ato interpretativo.

A despeito das intenções de Gadamer, os seus pressupostos teórico-filosóficos não deixaram de proporcionar o desenvolvimento de uma metodologia hermenêutica no campo das ciências sociais e humanas. O próprio Soares (1994) acaba por esboçar um percurso metodológico ao destacar que a interpretação envolve, com frequência, quatro componentes fundamentais: a) as pressuposições (pré-compreensões ou preconceitos) oferecidas pela tradição e que compõem nosso horizonte interpretativo; b) a tradição a partir da qual dialogamos com o objeto interpretado; c) os instrumentos metodológicos que distinguem a hermenêutica ordinária, da vida cotidiana, da interpretação para a produção de conhecimento científico; e d) a imaginação produtiva que instaura a reflexão crítica, de forma que a projeção das pré-compreensões não restrinja a atividade interpretativa em mera reiteração da tradição.

Em relação às contribuições metodológicas da teoria hermenêutica, Casal (1996) atribui a Paul Ricoeur o importante papel de fazer avançar a metodologia da interpretação, com considerável repercussão para o campo das ciências sociais e humanas, notadamente a Antropologia Interpretativa. Para tanto, Ricoeur assume como referência a própria reflexão teórico-filosófica de Gadamer. Em sua proposta teórico-metodológica, o autor se contrapõe aos pressupostos de Dilthey e Schleiermacher quanto à apreensão da intencionalidade do autor, ao que trata como equívoco de "pretender compreender um autor melhor do que ele a si mesmo compreendeu" (RICOUER apud CASAL, 1996, p. 63). O investimento teórico de Ricoeur será na busca de modos de objetivação dos processos linguísticos.

A metodologia hermenêutica, segundo Ricoeur (1989, p. 141), assume como objeto o texto, ou o discurso escrito, que define como "todo o discurso fixado pela escrita". A fixação do discurso preserva-o, uma vez que todo enunciado oral caracteriza-se pela sua transitoriedade, tendendo a desaparecer. Por outro lado, admite-se que a fixação do discurso garante mais do que a sua mera preservação. Ela afeta a sua função comunicativa (RICOEUR, 1976).

Outra consequência da fixação do discurso é a transformação da situação dialógica caracterizada pelo encontro face a face entre os sujeitos da conversação. Deste modo, a intenção do autor e a significação do texto dissociam -se. O resultado é a autonomia semântica do texto, passando a prevalecer o "dito como tal" (RICOEUR, 1976, p. 21). Em outras palavras, o que o texto significa interessa mais do que o autor quis dizer ao enunciá-lo ou escrevê-lo.

A autonomia semântica do texto é um conceito-chave para a Hermenêutica, segundo Ricoeur (1976). A autonomia não implica em perda de referências do texto, que "permanece um discurso dito por alguém, dito por alguém a mais alguém acerca de alguma coisa" (RICOEUR, 1976, p. 42).

A autoria do texto figura, entretanto, como uma de suas dimensões. Não estando mais presente na situação de produção do texto, o autor já não pode ser interrogado pelo leitor ou intérprete. Por outro lado, o texto caracteriza -se por sua abertura a leitores indefinidos capazes de múltiplas interpretações. Nessa possibilidade, situa-se a dialética da autonomia semântica do texto: "a hermenêutica começa onde o diálogo acaba" (RICOEUR, 1976, p. 43). É deste modo que a interpretação pode objetivar-se (CASAL, 1996).

A exterioridade do discurso fixado em texto repercute, ainda, no distanciamento entre autor e leitor. 
As referências do texto já não são limitadas à situação de diálogo face a face, fazendo possível o acesso ao mundo por intérpretes indefinidos, tendo em vista que a fixação do discurso possibilita a transcrição do mundo: "compreender ou interpretar um texto consistirá, então, em confrontá-lo com todas as significações possíveis" (CASAL, 1996, p. 64).

Nessa perspectiva, Ricoeur (1976) afirma ser a exterioridade uma condição necessária à Hermenêutica, via processos de distanciação. Ao distanciar-se do autor, o texto pode aproximar-se do leitor ou intérprete, abrindo-se assim, segundo Casal (1996), a novos horizontes referenciais. A apreensão de sentidos envolve o apropriar-se do que é alheio, estranho, não-familiar. Essa é a essência da dialética distanciação/apropriação, manifesta na interpretação hermenêutica.

\section{Sistema de Signos, Significados e Práticas e o trabalho de campo em saúde mental}

Em conformidade com um referencial teórico-metodológico fundamentado na tradição hermemêutica gadameriana e em autores da antropologia interpretativa, o Sistema de Signos, Significados e Práticas - S/ssp (BIBEAU, 1992; BIBEAU e CORIN, 1995; ALMEIDA-FILHO, et. al. s/d; s/d(a); ALMEIDA-FILHO, COELHO e PERES, 1999; CAROSO, RODRIGUES e ALMEIDA-FILHO, 1996; 1998) tem sido adotado como uma das possibilidades de operacionalização do trabalho de campo em pesquisas qualitativas em saúde mental desenvolvidas por pesquisadores do Nisam. Esse modelo metodológico se dispõe ao articular os contextos micro e macrosociais, propondo um método de trabalho que focaliza as experiências subjetivas e trajetórias singulares das pessoas em situações concretas, prezando por considerar as condições estruturantes e a experiência organizadora coletiva que as sustentam (BIBEAU, 1992).

O S/ssp foi elaborado com o objetivo inicial de ser uma alternativa de investigação para o campo da Psiquiatria Transcultural, a partir da integração das perspectivas interpretativa, fenomenológica e social, desenvolvendo a Antropologia Crítica. Nessa direção, parte da revisão dos limites da abordagem epidemiológica dos transtornos mentais, tendo como objeto de estudo os problemas de saúde mental (BIBEAU, 1992; BIBEAU e CORIN, 1995; ALMEIDA-FILHO, et.al. s/d; sd(a); ALMEIDAFILHO, COELHO e PERES, 1999).

A proposta do S/ssp, na coleta de dados, considera três etapas metodológicas: pré-enquete, enquete extensiva e reconstrução de casos. A pré-enquete tem como objetivo conhecer os signos associados às pessoas socialmente problemáticas, surgidos espontaneamente em diálogos sobre o problema investigado. Na enquete- extensiva, identificam-se os interlocutores-chave, conhecendo-se os signos e seus significados através de entrevistas abertas, explorando-se casos concretos. No terceiro momento, há propriamente a reconstrução de casos, focalizando aspectos como causas da doença, gravidade atribuída, reações com relação à pessoa afetada e à doença e tratamentos realizados (CAROSO, RODRIGUES e ALMEIDA-FILHO, 1996; 1998; ALMEIDA-FILHO et. al. s/d; s/d (a)).

O S/ssp é constituído de três níveis para a abordagem de um problema de investigação: o factual, o narrativo e o interpretativo (BIBEAU, 1992). O início da coleta dos dados é um ponto de partida significativo para capturar o ponto de vista dos interlocutores, que se estende valorizando também o trabalho do pesquisador até a finalização do trabalho interpretativo. No primeiro nível, factual, partese da ideia de que é preciso levantar fatos, eventos e ações concretas significativas para os sujeitos da pesquisa. Além disso, recolher dados complementares diversos, inclusive estatísticos relacionados ao problema (BIBEAU, 1992).

O nível narrativo diz respeito à coleta inicial de relatos espontâneos sobre a problemática e identificação dos interlocutores-chave. Em um segundo momento, mais sistemático, refere-se à reconstrução propriamente dita das experiências dos interlocutores que lidam cotidianamente com a problemática. Nesse particular, é prudente ressaltar que as narrativas são as principais unidades de análise da proposta, e não os casos propriamente ditos, marcando um outro tipo de delineamento de pesquisa, que não o de estudo de caso advindo da Clínica Médica e Psicológica, ou da corrente sociológica (BIBEAU, 1992).

Por fim, o nível interpretativo implica em considerar as interpretações dos interlocutores enquanto uma interpretação nativa, à qual o pesquisador não pode se limitar. Consideramos que a Hermenêutica Antropológica requer a passagem da mera descrição dos fatos e modelos explicativos nativos para a elaboração de uma interpretação, ou seja, um trabalho cooperativo analítico que propicie a emergência dos sentidos que podem escapar aos atores sociais (BIBEAU, 1992).

Nesse terreno, cabe ressaltar que a inspiração no modelo S/ssp nos conduziu a compartilhar duas de suas questões operacionais: 1) as vantagens de considerar as narrativas produzidas pelos interlocutores (por exemplo, quando representantes de um campo científico, ou seja, não leigos) 
como qualquer conhecimento localmente construído, portanto, plural, fragmentado e até contraditório como ponto de partida para a sua compreensão; 2) a ideia de que suas histórias concretas particulares na vivência dos desafios da atuação em situações de trabalho em saúde pública, particularmente no campo da saúde mental, não devem ser lidos como "textos autônomos", no sentido de resumi-los a experiências subjetivas e reificar as narrativas, incluindo a ideia de que os significados devem ser compreendidos a partir de um determinado contexto sociocultural (BIBEAU, 1992).

Ainda para o nível interpretativo, os autores consideram que a Hermenêutica de segundo nível é uma estratégia que combina a submissão ao texto dos discursos coletados e a violência feita pelo pesquisador sobre estes textos. Nessa direção, o processo de interpretação dá-se a partir de quatro regras básicas apresentadas em aforismos por Bibeau e Corin (1995).

O primeiro diz respeito ao fato de ser necessário "adquirir familiaridade com a superfície da realidade", traduzido no esforço de ganhar familiaridade com o mundo do nativo, aprendendo sua língua, seus costumes e conhecendo suas atividades. O segundo aforismo está relacionado à capacidade de "olhar por trás dos cenários e ler nas entrelinhas", ou seja, não se limitar ao que é dado superficialmente, mas descortinar as camadas da realidade, buscando os significados intencionais ou voluntariamente escondidos. Nesse sentido, considerando a analogia da cultura como textos (GEERTZ, 1989) produzidos na interação do pesquisador com e sobre seus informantes, buscar o "subtexto da cultura"; os interstícios, os silêncios e os múltiplos disfarces dos conceitos nativos.

A terceira máxima, "seguir os passos dos adivinhos", retrata dois sentidos: a) a seleção de pessoas, autoridades, contadores de histórias, ou seja, informantes-chaves que se autorizam a narrar suas experiências e que são pessoas conhecedoras do objeto de interesse do pesquisador; além disso: $b$ ) considerar que o processo interpretativo é da mesma natureza da "adivinhação", não no sentido mágico da tarefa, mas que advém da possibilidade de o pesquisador conectar os signos por ele selecionados, identificando-os dentro de um sistema de significados ou modo de pensamento que prevalece dentro do grupo estudado.

Por fim, a quarta regra para desenvolver a interpretação antropológica sob bases confiáveis ressalta que cabe ao pesquisador "se comprometer no esforço cooperativo criativo" para compreender a realidade estudada. Nesse sentido, é preciso considerar que a interpretação dos textos implica numa cooperação entre o escritor e o leitor (RICOEUR, 1989; 1991) que deve ser capaz de preencher os espaços vazios. Por outro lado, considerar que os informantes são coautores ao fornecerem as interpretações nativas. Como ressaltam Bibeau e Corin (1995, p. 60), "o significado não é nunca um produto coletivo já dado, mas esse é, em vez disso, incessante e cooperativamente criado pelos atores culturais, negociado entre eles sobre diferentes estágios, e publicamente revelados [tradução nossa]".

Em síntese, para os referidos autores, o processo submissão-violência dos achados etnográficos implica em uma Hermenêutica Antropológica desenvolvida no permanente esforço de tornar a realidade estudada cada vez mais familiar aos olhos do pesquisador, de modo a possibilitar captar os significados que fugiriam à percepção superficial das situações encontradas. Além disso, busca-se preencher os espaços vazios dos textos produzidos, com o intuito de acessar os modos de pensamentos que prevalecem no grupo estudado.

No sentido mais operacional, na etnografia focalizada, "a análise dos dados etnográficos deve conduzir à identificação de padrões e pontos focais em torno das amplas partes da vida cultural e social, organizadas em cada contexto" [tradução nossa] (ALMEIDA-FILHO e outros s/d (a). Nessa perspectiva, a etnografia focalizada é uma estratégia metodológica que busca descrever os aspectos significativos do contexto estudado para melhor delimitação do problema de investigação, explorando aqueles que o envolvem ou o sustentam não como informações complementares e dadas a priori, mas como produzidos cotidianamente na realidade de estudo.

Podemos destacar algumas premissas epistemológicas que têm norteado o trabalho de campo em pesquisas desenvolvidas pelo Nisam, enunciadas em quatro noções fundamentais como: objetomodelo, validade relativa, representatividade fraca, sensibilidade contextual (ALMEIDA-FILHO, CORIN e BIBEAU, s/d). Tomar um objeto de investigação como objeto-modelo implica em considerá-lo o "resultado da redução de traços selecionados de um fenômeno concreto dentro de categorias gerais universais" [tradução nossa] (ALMEIDA-FILHO, CORIN e BIBEAU, s/d), assumindo uma perspectiva praxiológica, ou seja, enfatizando a compreensão dialógica da produção de conhecimento. Trata-se de distanciar-se das abordagens que percebem o objeto como uma "representação direta da realidade" e que ignoram a sua emergência dentro de uma complexa relação de poder, inerente aos contextos institucionais e às teias sociais e políticas que a legitimam. $O$ que não implica necessariamente propor que a realidade social só exista condicionada à sua interpretação. 
Segundo, a validade dos achados e interpretações está condicionada à apresentação do caminho adotado e da explicitação de noções importantes para a sua compreensão. Por isso, seu caráter é relativo. Por outro lado, podemos atribuir uma validade relativa ao conhecimento produzido, uma vez que ele é simultaneamente influenciado pela modelação do objeto e pelo contexto social, histórico e cultural, no qual é desenvolvido (ALMEIDA-FILHO; CORIN e BIBEAU, s/d).

A noção de representatividade fraca quer assegurar o caráter eminentemente qualitativo do modelo adotado em contraponto à pesquisa com métodos estruturados (quantitativa), cuja escolha dos informantes-chaves obedece o potencial de heterogeneidade que os entrevistados possam revelar ao grupo estudado e a diversidade discursiva para compreensão do objeto, e não corresponde às normas das investigações sob a égide do métodos estruturados, que se orientam em procedimentos estatísticos para definirem sua amostragem (ALMEIDA-FILHO; CORIN e BIBEAU, s/d).

Por fim, a sensibilidade cultural do modelo S/ssp busca enfatizar o compromisso do pesquisador com a produção contextualizada do conhecimento científico. Dito de outro modo, seguir na direção de valorizar a interpretação local, revelada na identificação dos signos e compreensão dos significados que são atribuídos ao objeto-modelo, como um ponto de partida fundamental de trabalho que valorize o particular e que não perca de vista as reflexões acerca dos seus aspectos universais (ALMEIDA-FILHO; CORIN e BIBEAU, s/d).

Podemos destacar ainda como algumas das noções que sustentam a Antropologia Interpretativa (GEERTZ, 1989; 1989a; 2002; 2002a) têm se mostrado muito úteis para a compreensão de objetos de pesquisa em saúde mental. É importante ressaltar que muitas das orientações do S/ssp estão em confluência com a perspectiva interpretativa de Clifford Geertz, ainda que se deva demarcar a busca de refinamento dos pesquisadores do $\mathrm{S} / \mathrm{ssp}$, particularmente por sistematizarem um método de coleta e análise dos dados etnográficos sobre os problemas de saúde.

A principal dessas noções está na problematização de que a vida social pode ser compreendida a partir da metáfora do texto. No trabalho de Geertz (2002a) e seus seguidores, a noção de texto que sustenta a Antropologia Interpretativa fundamenta-se, principalmente, nas reflexões filosóficas de Paul Ricoeur. A metáfora do texto aparece como um recurso potente no momento fundador de uma nova corrente antropológica, apresentando uma específica relação entre a produção dialógica proveniente do trabalho de campo e a sua interpretação a posteriori (GEERTZ, 1989; 2002)

Nesse sentido, a analogia da vida social como um texto que pode ser lido é inspirada no conceito de inscrição desenvolvido por Paul Ricoeur, que é "a chave para a transição de texto para o texto análogo, ou de um texto escrito como discurso para a ação como discurso" (GEERTZ, 2002a, p. 50). Para Ricoeur (1991, p. 106), como dito anteriormente, "texto é todo discurso fixado pela escrita" e inscrição é a fixação do significado em alguma forma de registro.

A Antropologia Interpretativa parte dessa perspectiva, considerando que a própria ação é constituída de significados e que pode ser lida como um texto. Do ponto de vista da escrita etnográfica interpretativa, inscrever a ação possibilita-nos a passagem da mera descrição dos fatos e modelos explicativos nativos para a elaboração de uma interpretação do pesquisador (GEERTZ, 1989; 2002; 2002a).

Partindo da noção de inscrição da ação, (198Geertz 9) afirma que a descrição etnográfica é interpretativa e microscópica. O que se interpreta é o fluxo do discurso social, buscando salvar o "dito", evitando assim a sua extinção e fixando-o em formas pesquisáveis. O sentido atribuído à característica microscópica da descrição autoriza a ressalva de que "interpretações mais amplas e análises mais abstratas" surgem de "um conhecimento muito extensivo de assuntos extremamente pequenos". Há também a consideração de que, ao assim qualificá-la, evita-se que o lócus do estudo coincida necessariamente com o objeto de estudo, comum em estudos antropológicos mais clássicos (GEERTZ, 1989).

Consideramos a força da experiência vivenciada (GEERTZ, 1989), ressaltando a possibilidade de acessar os seus significados através da prática etnográfica, na busca de conhecer como pensam e sentem os sujeitos. Cabe ao pesquisador registrá-las, seja provocando os interlocutores com técnicas de coleta de dados - entrevistas, por exemplo - ou fazendo observações diretas e/ou participativas.

\section{Reflexões finais}

A problematização acerca dos significados das novas formas de cuidado em saúde mental, assumindo como campo empírico privilegiado o Centro de Atenção Psicossocial e o seu território, encontra-se no cerne de reflexões teórico-metodológicas tecidas pelo Nisam e aqui compartilhadas. Ao longo do 
trabalho de campo, os diálogos produzidos no cotidiano dos CAPS ou no território (o dizer) desaparecem temporariamente com o momento da ação no âmbito do serviço e/ou do território (atividades desenvolvidas, passeios, movimentação no bairro/comunidade), mas os significados (o que foi dito) permanecem, principalmente, e não exclusivamente, na inscrição (fixação do significado), sendo possível conhecê-los do ponto de vista do nativo-usuários/familiares/profissionais, considerando as possíveis relações estabelecidas com elementos mais amplos da realidade, sejam os institucionais, culturais, sociais ou políticos (GEERTZ, 2002).

No entanto, é preciso outra advertência: estamos no lugar de quem "lê" e não de quem "escuta", quando do tratamento dos dados coletados. Nesse particular, temos que considerar dois momentos distintos da produção dos dados e, consequentemente, da sua análise. Primeiro, as entrevistas e/ou observações são realizadas por um grupo de pesquisadores, momento em que está no papel de quem escuta e produz um diálogo com seus informantes-chaves. Na perspectiva adotada, já produz uma interpretação, menos consciente, sobre o que é falado e segue o seu fluxo, ainda que orientada por um roteiro.

No segundo momento, a análise das narrativas nos coloca no papel de quem lê, que é enriquecido pela prévia participação na produção direta das narrativas que serão as suas unidades de análise, mas que não se limita a este momento nem a tornaria inviável se não houvesse participado da referida produção: o dito inscreve-se.

Essa observação se faz especialmente importante para o processo de análise e interpretação de dados empíricos pelo grupo de pesquisa. O Nisam, por exemplo, em sua última pesquisa, desenvolveu um trabalho de campo de dois anos com o objetivo de avaliar as novas formas de cuidado em saúde mental com participação de 11 CAPS, sete deles na Bahia e quatro em Aracaju. Obteve-se um banco de dados de cunho etnográfico bastante vasto, o qual tem sido utilizado interpretativamente por integrantes do grupo, sem que, no entanto, haja coincidência entre o CAPS em que ele coletou os dados (participou diretamente da produção dos diálogos) com aqueles que incluem em uma das suas análises a posteriori, em diversos recortes interpretativos.

Partimos da premissa de que o ato da leitura é diferente do ato do diálogo. Uma característica importante que marca essa diferença é que a escrita preserva o discurso e o torna disponível para a memória individual e coletiva. Segundo o autor, o diálogo está para a fala, assim como a escrita está para a leitura, uma vez que a escrita toma o lugar do discurso. Porém, para o autor não há supremacia entre a fala e a escrita: "o que aparece na escrita é o discurso enquanto intenção de dizer e [...] a escrita é uma inscrição direta desta intenção, mesmo se, histórica e psicologicamente, a escrita começou por transcrever graficamente os signos da fala" (RICOEUR, 1989, p. 143).

Considerar que o texto toma o lugar do discurso (RICOEUR, 1989), ou seja, da vida social, parece ser um dos estímulos para o desenvolvimento da perspectiva interpretativa da Antropologia e indica-nos que essa aproximação vai além da noção de inscrição e chega à própria noção de interpretação. Essa noção baseia-se na separação do texto produzido no que diz respeito à oralidade, cuja liberação transforma as relações entre a linguagem e o mundo e, além disso, a relação entre a linguagem e as subjetividades do autor e do leitor.

Ler um texto significa interpretá-lo, ou seja, apropriar-se do que, inicialmente, era estranho, no sentido de diminuir a distância cultural (RICOEUR, 1989; 1991). A tarefa da leitura é efetuar a referência para o mundo e para o sujeito, atualizando a ambiência e a audiência. Do ponto de vista de Ricoeur, a escrita reivindica a leitura e isso modifica a relação autor-leitor, coloca o leitor no lugar de quem produz uma interpretação seguindo a própria interpretação oferecida no texto. ${ }^{2}$

Essa noção reflete a perspectiva interpretativa proposta por Geertz. A tarefa do pesquisador, ou a própria prática etnográfica, tem por vocação conhecer o mundo do ponto de vista do nativo. No entanto, adverte-nos de que:

" O etnógrafo não percebe - principalmente não é capaz de perceber - aquilo que seus informantes percebem. O que ele percebe, e mesmo assim com bastante insegurança, é o "com que", ou "por meios de que", ou "através de que" (ou seja lá qual for a expressão) os outros percebem". (GEERTZ, 2002, p. 89)

Para Geertz (2002), a interpretação pode ser também exemplificada como sendo a passagem da experiência próxima à experiência distante. Por experiência próxima entende-se o uso natural e sem esforço de explicações sobre o que os semelhantes veem, sentem, pensam e imaginam que os demais membros do grupo entenderiam facilmente; por sua vez, a experiência distante é outra interpretação, não menos válida do que a anterior, elaborada para alcançar objetivos científicos, filosóficos ou práticos. 
No terreno da interpretação, ao pesquisador cabe não se limitar à experiência-próxima, mas considerá-la como ponto fundamental de partida. Tomamos os relatos dos nossos interlocutores como produzindo conceitos de experiência-próxima, ainda que, em alguns momentos, eles façam uso de conceitos que vêm de experiência-distante, pois são também especialistas. Segundo Geertz (2002), não há diferença normativa entre tais conceitos, ou seja, um não é melhor do que o outro. Há uma diferença de grau, e não de oposição extrema.

Destacamos essas ideias para ressaltar a capacidade dos interlocutores produzirem sentido em situações concretas e, além disso, considerar o papel ativo do pesquisador na leitura dos textos produzidos cooperativamente com seus informantes. Nessa direção, Bibeau (1992) ressalta que, no processo interpretativo, é preciso recuperar a responsabilidade e autonomia dos atores sociais e deles próprios, sem, no entanto, negligenciar os fatores políticos, sociais e culturais que se impõem nas suas explicações e decisões em situações concretas.

Por fim, há mais uma observação a ser registrada que envolve o uso da metáfora do texto como estratégia para o entendimento da realidade social: a promessa de uma interpretação que preza por ressaltar "a ação a seu significado, e não o comportamento a seus determinantes" (GEERTZ, 2002a p. 55). Não buscamos associações positivas entre variáveis, presas à relação causa e efeito; buscamos os significados que são atribuídos às ações a partir de situações concretas.

\section{Referências bibliográficas}

ALMEIDA-FILHO, N., COELHO, M.T, PERES, M.F. Conceito de Saúde Mental. Revista USP, São Paulo, n. 43, p. 100-125, set/nov, 1999.

ALMEIDA-FILHO, N.et.al. Signos, significados e práticas em saúde mental: desafio metodológico e experiência de campo. s/d. digitado.

ALMEIDA-FILHO, N.; CORIN, E.; BIBEAU, G. Rethinking transcultural approaches to mental health research: from epistemology to methodology. Montréal: Département d'Anthropologie/Université de Montréal, Research Report n. 2. 1998.

ALMEIDA-FILHO, N; et. al. E. Signs, meanings and practices in mental health: partII. Methodologycal apllication the Bahia study. s/d (a). digitado.

BIBEAU, G e CORIN, E. (eds.). Beyond textuality. Ascetism and violence in anthropological interpretation approaches to semiotics series. Berlin, Mounton De Gruyter, 1995.

BIBEAU, G. ?Hay uma enfermedad em las americas? Outro camino de la antropologia médica para nuestro tiempo. VI Congreso de Antropologia em Colombia. Universidad de los Andes: Santa Fé de Bogotá, Julio, 1992.

BRASIL. Portaria GM n o. 336, de 19 de fevereiro de 2002.In: BRASIL. Ministério da Saúde. Secretaria-Executiva. Secretaria de Atenção à Saúde. Legislação em saúde mental: 1990-2004. 4. ed. rev. e atual. Brasília: Ministério da Saúde, 2004. p. 125-136.

CAROSO, C., RODRIGUES, N. e ALMEIDA-FILHO, N. Manejo Comunitário em Saúde Mental e Experiência da Pessoa. Horizontes Antropológicos, Porto Alegre, v. 9, p. 63-83, 1998.

CAROSO, C., RODRIGUES, N. e ALMEIDA-FILHO, N. Estudo de Signos, Significados e Práticas em Saúde Mental em Conde-Bahia. Projeto de Pesquisa-CNPq, 1996.

CASAL, A.Y. Para uma epistemologia do discurso e da prática antropológica. Lisboa: Edições Cosmos, 1996.

FURTADO, J.P. Um método construtivista para a avaliação em saúde. Ciência \& Saúde Coletiva, v.6, n.1, p.165-181, 2001.

FURTADO, J.P.; CAMPOS, R.O. Participação, produção de conhecimento e pesquisa avaliativa: a inserção de diferentes atores em uma investigação em saúde mental. Cadernos de Saúde Pública, v.24, n.11. p. 2671-2680, 2008.

GEERTZ, C. Do ponto de vista dos nativos: a natureza do entendimento antropológico. In: , 0 saber local: novos ensaios de antropologia interpretativa. 5 ed. Petrópolis: Vozes, 2002. p. 85107.

GEERTZ, C. Mistura de gêneros: a reconfiguração do pensamento social. In: O saber local: 
novos ensaios de antropologia interpretativa. 5 ed. Petrópolis: Vozes, 2002a. p. 33-56.

GEERTZ, C. Pessoa, Tempo e Conduta em Bali. In: A interpretação das culturas. Rio de Janeiro: LTC, 1989a. p. 225-277.

GEERTZ, C. Uma descrição densa: por uma teoria interpretativa da cultura. In: $\mathbf{A}$ interpretação das culturas. Rio de Janeiro: LTC, 1989. p. 13-41.

MINAYO, M.C.S. Abordagem antropológica para avaliação de políticas sociais. Revista de Saúde Pública, v.25, n.3, p.233-238, 1991.

MINAYO, M.C.S. Introdução: conceito de avaliação por triangulação de métodos. In: MINAYO, M.C.S.; ASSIS, S.G.; SOUZA, E.R. (Orgs.). Avaliação por triangulação de métodos : abordagem de programas sociais. Rio de Janeiro: Fiocruz, 2005. p. 19-51.

NUNES, M. et al.. A articulação da experiência dos usuários nas microculturas dos Centros de Atenção Psicossocial \&- uma proposta metodológica. Estudos e Pesquisa em Psicologia, v.10, n.1, p.204220, 2010.

ONOCKO-CAMPOS, R.T.; FURTADO, J.P. Entre a saúde coletiva e a saúde mental: um instrumental metodológico para avaliação da rede de Centros de Atenção Psicossocial (CAPS) do Sistema Único de Saúde. Cadernos de Saúde Pública, v.22, n.5, p. 1053-1062, 2006.

RICOEUR, P. Da. Do texto a acção: ensaios de hermenêutica I I . Portugal: RÉS-Editora, 1989. RICOUER, P. Teoria da interpretação: o discurso e o excesso de significado. Lisboa: Edições 70, 1976.

SANTOS, M.R.P.; NUNES, M.O. Territory and mental health: a study on the experience of users of a psychosocial care center, Salvador, Bahia. Interface - Comunic., Saude, Educ. , v.15, n.38, p.71526, jul./set. 2011.

SANTOS, B. S. Um discurso sobre as ciências. 7ed. Porto: Afrontamento, 1995.

SANTOS, M. O retorno do território. In: SANTOS, M. et al. Território, globalização e fragmentação. São Paulo: HUCITEC/ANPUR, 1994. p.15-20.

SCHELEIERMACHER, F.D.E. Hermenêutica: arte e técnica da interpretação. 5 ed. Bragança Paulista, SP: Editora Universitária São Francisco, 2006.

SCHUTZ, Alfred. Fenomenologia e relações sociais. Rio de Janeiro: Zahar, 1979.

SOARES, L.E. O rigor da indisciplina. Rio de Janeiro: Relumé/ Dumará, 1994.

\section{Notas}

1 Texto submetido ao número temático da Revista RECIIS - Revista Eletrônica de Comunicação, Informação e Inovação em Saúde, do Instituto de Comunicação e Informação Científica e Tecnológica em Saúde, da Fundação Oswaldo Cruz, Brasil, dedicado ao tema 'Saúdes, Corpos e Contextos Interculturais'. Dezembro de 2011.

2 "Quando o texto toma o lugar da fala, já não podemos falar propriamente de locutor, pelo menos, no sentido de uma auto-designação imediata e directa daquela que fala na instância de discurso: a esta proximidade do sujeito falante com a sua própria fala substitui-se uma relação complexa do autor com o texto que permite dizer que o autor é instituído pelo texto, que ele próprio se mantém no espaço de significação traçado e inscrito na escrita; o texto é exatacmente o lugar onde o autor sobrevive" (RICOEUR, 1989, p. 145) 